\title{
Effect of Heat Stress and Stocking Density on Growth Performance, Breast Meat Quality, and Intestinal Barrier Function in Broiler Chickens
}

\author{
Doyun Goo, Jong Hyuk Kim, Geun Hyeon Park, Jomari Badillo Delos Reyes $\mathbb{D}^{\mathbb{D}}$ and \\ Dong Yong Kil * (D)
}

Department of Animal Science and Technology, Chung-Ang University, Anseong-si, Gyeonggi-do 17546, Korea; Less1598@naver.com (D.G.); mrdgj7@naver.com (J.H.K.); pgh9210@naver.com (G.H.P.);

jomdelosreyes@gmail.com (J.B.D.R.)

* Correspondence: dongyong@cau.ac.kr; Tel.: +82-31-670-3028

Received: 18 February 2019; Accepted: 19 March 2019; Published: 21 March 2019

check for updates

Simple Summary: There is limited information on the interactive effects of heat stress (HS) and stocking density (SD) on broiler chickens. Our results indicated that both HS and high SD decreased broiler performance. HS affected intestinal barrier function by increasing intestinal permeability, but this result was not found with high SD. No interactive effects were observed between HS and SD for growth performance, meat quality, and intestinal barrier function in broiler chickens.

\begin{abstract}
The present experiment was conducted to investigate the effect of heat stress (HS) and stocking density (SD) on growth performance, breast meat quality, and intestinal barrier function in broiler chickens. Experimental treatments included two different ambient temperatures $\left(20^{\circ} \mathrm{C}\right.$ : thermoneutral conditions, or $27.8^{\circ} \mathrm{C}$ : HS conditions) and two different SD (low: 9 birds $/ \mathrm{m}^{2}$ and high: 18 birds $/ \mathrm{m}^{2}$ ) in a $2 \times 2$ factorial arrangement. A total of 1140 21-day-old broiler chickens were allotted 1 of 4 treatments with five replicates. At the end of the experiment ( 35 days of age), two birds per replicate were euthanized for sample collections. The results indicated no interactions between HS and SD for all measurements. For main effects, HS decreased $(p<0.05)$ the growth performance of broiler chickens. Similarly, high SD also decreased $(p<0.05)$ body weight gain and feed intake. HS decreased $(p<0.01)$ jejunal trans-epithelial electric resistance (TER), whereas high SD did not affect TER. Neither HS nor high SD affected jejunal tight junction-related gene expressions; however, high SD reduced $(p<0.05)$ occludin expression. In conclusion, HS and high SD are key environmental factors decreasing broiler performance; however, the interactive effects of HS and high SD are not significant under the current conditions.
\end{abstract}

Keywords: broiler chicken; heat stress; intestinal barrier function; stocking density; tight junction-related gene expression

\section{Introduction}

In the current livestock industry, animals are raised under various stressful conditions, such as high ambient temperature, high rearing density, disease challenges, low sanitation, and improper management, which threaten the productive performance, health status, and well-being of animals. Therefore, animal researchers have made many efforts to ameliorate the stress responses of animals. However, because of limited information regarding the physiological mechanisms affecting stress responses in animals exposed to various stressors, few promising strategies have been developed.

As environmental temperature is steadily increasing worldwide, heat stress (HS) is considered one of the major challenges for the livestock industry in many countries. Among livestock animals, 
poultry are the most vulnerable to HS because poultry lack the ability to dissipate body heat production owing to feather covering and limited sweat glands [1]. Therefore, poultry exposed to HS frequently experience various physiological disturbances, such as systemic immune dysregulation, endocrine disorders, respiratory alkalosis, and electrolyte imbalance [2-4], which decrease poultry health and performance. In addition, one of the physiological challenges associated with these negative outcomes is an impaired intestinal barrier function [5,6]. Lambert [5] suggested that HS diverts blood flows from the gastrointestinal tract (GIT) to the skin, which damages the mucosal tight junction barrier in the GIT. This impaired barrier function increases intestinal permeability and, therefore, promotes the transfer of luminal endotoxins (e.g., lipopolysaccharides; LPS) into the body, which is related to an increase in local and systemic inflammatory responses.

Stocking density (SD) can also be a critical stressor in intensive poultry production because high SD is highly related to problems in the performance, health, and well-being of poultry $[7,8]$. The possible reasons for these problems are associated with decreased feed and water accessibility, abnormal behavior, and low air and floor quality [8,9]. Moreover, high SD can create a mild HS condition by increasing the temperature in microenvironments surrounding chickens and decreasing heat dissipation from the body $[9,10]$. Therefore, high SD may induce pathological responses similar to those of HS. Likewise, we previously reported that high SD decreased broiler performance and this negative effect was associated with impaired intestinal barrier function [11]. Therefore, it could be expected that the negative outcomes of high SD are exacerbated when poultry are exposed to HS. Najafi et al. [12] reported that blood stress hormones in broiler chickens were elevated when birds were raised at high SD and increased stress responses under high SD were more considerable for those birds exposed to HS. However, there is still limited information regarding the interactive effect of HS and SD in poultry. In addition, to the best of our knowledge, no experiments have been performed to study the interactive effect of HS and SD on intestinal barrier function of broiler chickens.

Therefore, the objective of the present experiment was to investigate the effect of HS and SD on growth performance, breast meat quality, and intestinal barrier function in broiler chickens.

\section{Materials and Methods}

\subsection{Birds, Experimental Design, and Management}

The protocol for this experiment was approved by the Institutional Animal Care and Use Committee at Chung-Ang University (IACUC, approval no. 201600108). The experiment was conducted in a completely randomized design with a $2 \times 2$ factorial arrangement, with two different ambient temperatures and two different SD. A total of 1140 21-day-old mixed Cobb growing broiler chickens were allotted to 1 of the 4 treatments with 5 replicates. The current experiment began with 21-day-old chickens because the effect of HS and SD is typically prominent during the growing phase of broiler chickens. Birds were stocked at either 9 birds $/ \mathrm{m}^{2}$ (low SD) or 18 birds $/ \mathrm{m}^{2}$ (high SD). Each SD was achieved by raising different numbers of birds (i.e., 38 birds for low SD and 76 birds for high $\mathrm{SD})$ per identical floor pen size $(2.0 \mathrm{~m} \times 2.4 \mathrm{~m})$ in an environmentally controlled room [11]. In the calculation of SD, however, floor space occupied by immobile objects $\left(0.584 \mathrm{~m}^{2}\right.$ for 2 feeders and 1 bell-shaped drinker per pen) was excluded. Thus, the final floor space for each pen was $4.216 \mathrm{~m}^{2}$. All floor pens were covered with a $10-\mathrm{cm}$ thick layer of rice hulls.

Birds from each SD were raised at either $20{ }^{\circ} \mathrm{C}$ (thermoneutral; TN conditions), or $27.8^{\circ} \mathrm{C}$ (HS conditions), on average for 2 weeks (i.e., from 21 days to 35 days of age). The TN conditions were set according to the Cobb Broiler Management Guide [13]. Electric heating appliances and gas heaters were used to maintain the designed ambient temperatures. Average relative humidity was $53.0 \%$ for both temperature conditions. Before the start of the experiment, all chickens were raised under the same environmental conditions and were fed the same starter diets. During the experiment, the commercial grower diet $\left(\mathrm{AME}_{\mathrm{n}}, 3,130 \mathrm{kcal} / \mathrm{kg} ; \mathrm{CP}, 21.0 \%\right.$; Ca, $0.90 \%$; available $\mathrm{P}, 0.38 \%$; Lys, $1.33 \%$; Met + Cys, $0.98 \%$ ) was fed to all birds. Diets and water were provided ad libitum. The entire 
experiment was performed under 24-hour lighting conditions. Body weight gain (BWG) and feed intake (FI) were recorded at the end of the experiment. Feed efficiency (FE) was calculated as BWG divided by FI after adjusting mortality [14].

\subsection{Sample Collection and Chemical Analysis}

At the end of the experiment, 2 birds per replicate, each with a body weight (BW) close to the average $\mathrm{BW}$ of each replicate, were euthanized by $\mathrm{CO}_{2}$ asphyxiation. One bird was used for analyzing breast meat quality, serum LPS, and jejunal tight junction-related gene expression, whereas the other bird was used for analyzing intestinal permeability.

Blood samples were collected by heart puncture using a red plain tube immediately after euthanization. Blood samples were then centrifuged at $3000 \times \mathrm{g}$ at $4{ }^{\circ} \mathrm{C}$ for 20 minutes to separate the serum and were stored at $-20^{\circ} \mathrm{C}$ before LPS analysis. The serum LPS concentrations were analyzed using a Microplate Reader (Molecular Device, Sunnyvale, CA, USA) and a commercial chicken LPS ELISA Kit (My Biosource, San Diego, CA, USA). The ELISA procedure was carried out according to the protocol of the manufacturer, and the absorbance was measured at $450 \mathrm{~nm}$. Mucosal samples from the jejunum of the small intestine were collected, frozen in liquid nitrogen, and stored at $-85^{\circ} \mathrm{C}$ until the subsequent analysis of gene expressions. For breast meat quality, the right portion of breast meat was used to analyze $\mathrm{pH}$ at 1 and $24 \mathrm{~h}$ postmortem using a $\mathrm{pH}$ meter (Hanna Instruments, Nusfalau, Romania), and the meat color at $24 \mathrm{~h}$ postmortem was measured based on the Commission Internationale de $1^{\prime}$ Eclairage (CIE) color scale for lightness $\left(\mathrm{L}^{*}\right)$, redness $\left(\mathrm{a}^{*}\right)$, and yellowness $\left(b^{*}\right)$. The left portion of the breast meat was used to measure water holding capacity (WHC) at $24 \mathrm{~h}$ postmortem and the thiobarbituric acid reactive substance (TBARS) value at 7 days after storage at $4{ }^{\circ} \mathrm{C}$ based on the methods described by Kim et al. [15].

The analysis of tight junction-related gene expression in the jejunal mucosa was performed with the method of Shin et al. [6]. Briefly, total RNA was extracted from the jejunal mucosa using TRIzol reagent (Invitrogen, Carlsbad, CA, USA) according to the manufacturer's instructions. Gene expression was examined for zonula occludens-1 (ZO-1), occludin (OCLN), claudin-1 (CLDN-1), and junctional adhesion molecule B (JAM-2). A quantitative RT-PCR was performed based on the general RT-PCR method using the LightCycler 96 system (Roche, Basel, Switzerland). Gene-specific primers for target genes were designed using NCBI/Primer-BLAST and the specificity of the primers was confirmed by PCR amplification, based on the procedure demonstrated by Aznar and Alarcon [16]. The primer sequences and amplification temperatures are listed in Table 1. The relative quantification of gene-specific expression was calculated using the $2^{-\Delta \Delta C t}$ method after normalization to glyceraldehyde-3-phosphate dehydrogenase (GAPDH) [17].

Table 1. Primers used for quantitative RT-PCR.

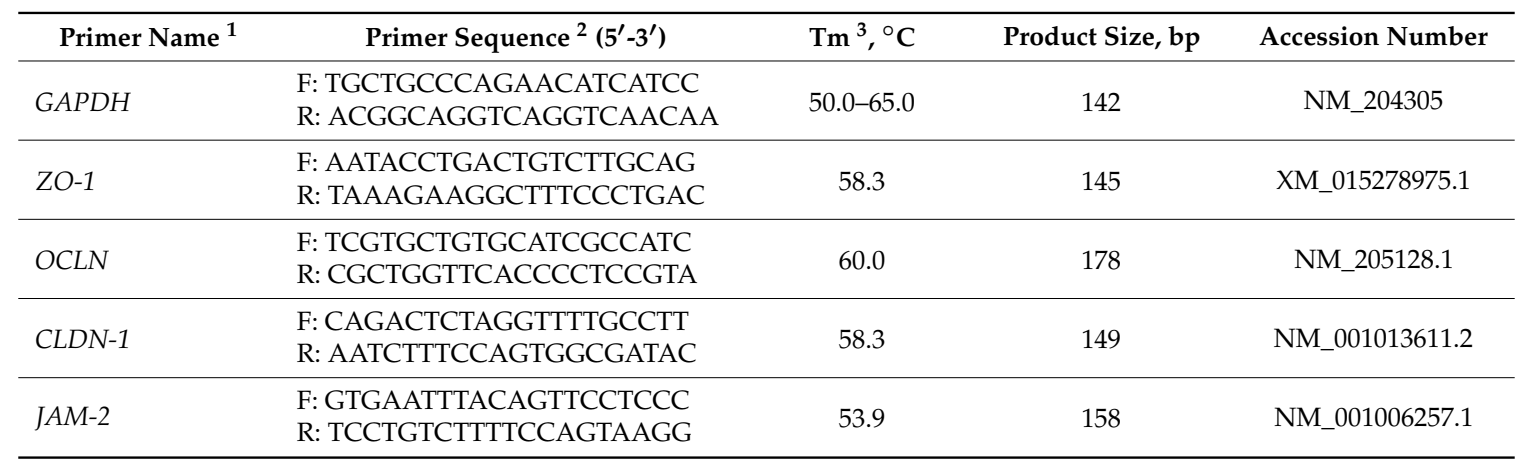

${ }^{1}$ GAPDH, glyceraldehyde-3-phosphate; ZO-1, zonula occludens-1; OCLN, occludin; CLDN-1, claudin-1; JAM-2, junctional adhesion molecules-B [11]. ${ }^{2} \mathrm{~F}$, forward; $\mathrm{R}$, reverse. ${ }^{3} \mathrm{Tm}$, melting temperature.

Intestinal permeability was measured by trans-epithelial electric resistance (TER) values in a 2-channel Ussing chamber system (U2500, Warner Instruments, Hamden, CT, USA). The detailed 
procedure has been reported previously [11]. In short, the mid-jejunum tissue samples (e.g., between the end of duodenal loop and Meckel's diverticulum) collected from selected birds were placed into chilled and aerated Krebs-Henseleit buffer at $\mathrm{pH}$ 7.4. The jejunum was cut into sections of 3 to $5 \mathrm{~cm}$, and adhering fat and mesenteries were removed. The prepared jejunal samples were then placed between the 2 halves of the Ussing chamber according to the method of Ruhnke et al. [18]. When samples were clamped in the Ussing chamber, the samples were continuously aerated with $95 \% \mathrm{O}_{2}$ and $5 \% \mathrm{CO}_{2}$ mixture, and completely immersed in Krebs-Henseleit buffer. The water jacket of the Ussing chamber was continuously circulated and heated to $38-39^{\circ} \mathrm{C}$. After stabilization, short circuit currents and the epithelial voltage were recorded. After $20 \mathrm{~min}$ of operation, TER values were calculated according to Ohm's law and were expressed as $\Omega / \mathrm{cm}^{2}[19]$.

\subsection{Statistical Analysis}

All data were analyzed by 2-way ANOVA in a completely randomized design with the MIXED procedure of SAS (SAS Institute Inc. Cary, NC, USA). The replicate was an experimental unit for all analyses. Outliers were checked using the UNIVARIATE procedure of SAS. The model included the effects of HS, SD, and their interaction. The LSMEANS procedure was used to calculate mean values. Significance for statistical test was set at $p<0.05$.

\section{Results}

During the two-week experiment, no interactions between HS and SD were identified for any of the measurements of growth performance, breast meat quality, and intestinal barrier function. Thus, only the main effects of HS and SD were reported.

\subsection{Growth Performance and Breast Meat Quality}

Birds raised under HS conditions had lower $(p<0.05)$ final BW, BWG, FI, and FE than those raised under TN conditions (Table 2). Breast meat quality was not affected by HS; however, breast meat from birds raised under HS conditions exhibited a greater $(p<0.05) 24-\mathrm{h}$ postmortem $\mathrm{pH}$ as compared to that from birds raised under TN conditions (Table 3).

Table 2. Effect of heat stress and stocking density on the growth performance of growing broiler chickens from 21 to 35 days of age.

\begin{tabular}{|c|c|c|c|c|c|c|}
\hline Item & & $\begin{array}{l}\text { Initial Body } \\
\text { Weight (g) }\end{array}$ & $\begin{array}{l}\text { Final Body } \\
\text { Weight (g) }\end{array}$ & $\begin{array}{l}\text { Body Weight } \\
\text { Gain (g) }\end{array}$ & $\begin{array}{c}\text { Feed Intake } \\
\text { (g) }\end{array}$ & $\begin{array}{c}\text { Feed Efficiency } \\
(\mathrm{g} / \mathrm{kg})\end{array}$ \\
\hline Temperature $^{1}$ & $\mathrm{SD}^{2}$ & & & & & \\
\hline \multirow[t]{2}{*}{ Thermoneutral } & 9 & 891 & 1918 & 1028 & 1902 & 540 \\
\hline & 18 & 886 & 1776 & 890 & 1799 & 494 \\
\hline \multirow{2}{*}{ Heat stress } & 9 & 895 & 1701 & 806 & 1666 & 483 \\
\hline & 18 & 883 & 1651 & 768 & 1583 & 486 \\
\hline $\operatorname{SEM}(n=5)$ & & 6.1 & 32.7 & 35.3 & 27.9 & 14.0 \\
\hline \multicolumn{7}{|l|}{ Main effect } \\
\hline \multicolumn{7}{|l|}{ Temperature } \\
\hline Thermoneutral & & 888 & 1847 & 959 & 1851 & 517 \\
\hline Heat stress & & 889 & 1676 & 787 & 1624 & 484 \\
\hline $\operatorname{SEM}(n=10)$ & & 4.3 & 23.1 & 25.0 & 19.7 & 9.9 \\
\hline \multicolumn{7}{|l|}{ SD } \\
\hline 9 & & 893 & 1810 & 917 & 1784 & 511 \\
\hline 18 & & 884 & 1713 & 829 & 1691 & 490 \\
\hline
\end{tabular}


Table 2. Cont.

\begin{tabular}{|c|c|c|c|c|c|c|}
\hline Item & & $\begin{array}{l}\text { Initial Body } \\
\text { Weight (g) }\end{array}$ & $\begin{array}{l}\text { Final Body } \\
\text { Weight (g) }\end{array}$ & $\begin{array}{l}\text { Body Weight } \\
\text { Gain (g) }\end{array}$ & $\begin{array}{c}\text { Feed Intake } \\
\text { (g) }\end{array}$ & $\begin{array}{c}\text { Feed Efficiency } \\
(\mathrm{g} / \mathrm{kg})\end{array}$ \\
\hline $\operatorname{SEM}(n=10)$ & & 4.3 & 23.1 & 25.0 & 19.7 & 9.9 \\
\hline$p$-Value & $\mathrm{df}$ & & & & & \\
\hline Temperature & 1 & 0.861 & $<0.001$ & $<0.001$ & $<0.001$ & 0.034 \\
\hline SD & 1 & 0.172 & 0.009 & 0.025 & 0.004 & 0.139 \\
\hline Temperature $\times$ SD & 1 & 0.556 & 0.177 & 0.178 & 0.720 & 0.103 \\
\hline
\end{tabular}

${ }^{1}$ Average ambient temperatures were $20^{\circ} \mathrm{C}$ and $27.8^{\circ} \mathrm{C}$ for thermoneutral conditions and heat stress conditions, respectively. ${ }^{2}$ Stocking density $=$ number of birds per square meter $\left(\right.$ birds $\left./ \mathrm{m}^{2}\right)$.

Table 3. Effect of heat stress and stocking density on the breast meat quality of growing broiler chickens.

\begin{tabular}{|c|c|c|c|c|c|c|c|c|c|}
\hline Item & & Yield, \% & $\mathrm{pH}, 1 \mathrm{~h}$ & $\mathrm{pH}, 24 \mathrm{~h}$ & WHC, \% & $\mathbf{L}^{*}$ & $a^{*}$ & $\mathbf{b}^{*}$ & TBARS \\
\hline Temperature $^{2}$ & $\mathrm{SD}^{3}$ & & & & & & & & \\
\hline \multirow{2}{*}{ Thermoneutral } & 9 & 16.4 & 6.1 & 5.8 & 75.6 & 54.4 & 3.0 & 7.1 & 0.171 \\
\hline & 18 & 15.0 & 6.1 & 5.8 & 78.4 & 51.4 & 2.5 & 6.3 & 0.201 \\
\hline \multirow[t]{2}{*}{ Heat stress } & 9 & 14.7 & 6.3 & 6.0 & 77.5 & 56.2 & 3.4 & 8.4 & 0.195 \\
\hline & 18 & 13.6 & 6.3 & 6.0 & 80.2 & 52.8 & 3.0 & 6.5 & 0.204 \\
\hline SEM $(n=5)$ & & 0.82 & 0.09 & 0.05 & 1.29 & 1.41 & 0.48 & 0.78 & 0.017 \\
\hline \multicolumn{10}{|l|}{ Main effect } \\
\hline \multicolumn{10}{|l|}{ Temperature } \\
\hline Thermoneutral & & 15.7 & 6.1 & 5.8 & 77.0 & 52.9 & 2.8 & 6.7 & 0.186 \\
\hline Heat stress & & 14.1 & 6.3 & 6.0 & 78.9 & 54.5 & 3.2 & 7.5 & 0.200 \\
\hline $\operatorname{SEM}(n=10)$ & & 0.58 & 0.06 & 0.04 & 0.91 & 1.00 & 0.34 & 0.55 & 0.012 \\
\hline \multicolumn{10}{|l|}{ SD } \\
\hline 9 & & 15.6 & 6.2 & 5.9 & 76.6 & 55.3 & 3.2 & 7.7 & 0.183 \\
\hline 18 & & 14.3 & 6.2 & 5.9 & 79.3 & 52.1 & 2.7 & 6.4 & 0.203 \\
\hline $\operatorname{SEM}(n=10)$ & & 0.58 & 0.06 & 0.04 & 0.91 & 1.00 & 0.34 & 0.55 & 0.012 \\
\hline$p$-Value & $\mathrm{df}$ & & & & & & & & \\
\hline Temperature & 1 & 0.071 & 0.082 & 0.012 & 0.168 & 0.282 & 0.373 & 0.339 & 0.445 \\
\hline SD & 1 & 0.138 & 0.679 & 0.740 & 0.046 & 0.038 & 0.332 & 0.113 & 0.261 \\
\hline Temperature $\times$ SD & 1 & 0.843 & 0.679 & 0.626 & 0.954 & 0.895 & 0.902 & 0.491 & 0.551 \\
\hline
\end{tabular}

${ }^{1}$ WHC, water holding capacity; $\mathrm{L}^{*}$, lightness; $\mathrm{a}^{*}$, redness; $\mathrm{b}^{*}$, yellowness; TBARS, thiobarbituric acid reactive substances (mg of malondiadehyde $/ \mathrm{kg}$ ). ${ }^{2}$ Average ambient temperatures were $20^{\circ} \mathrm{C}$ and $27.8^{\circ} \mathrm{C}$ for thermoneutral conditions and heat stress conditions, respectively. ${ }^{3}$ Stocking density $=$ number of birds per square meter $\left(\mathrm{birds} / \mathrm{m}^{2}\right)$.

Birds raised at high SD had lower $(p<0.05)$ final BW, BWG and FI than those raised at low SD. Birds raised at high SD showed a greater WHC $(p<0.05)$ but a lower $(p<0.05) \mathrm{L}^{*}$ value in the breast meat than those raised at low SD. However, high SD had no effects on other meat qualities.

\subsection{Intestinal Barrier Function}

Birds raised under HS conditions had lower $(p<0.01)$ TER values than birds raised under TN conditions, indicating that HS increased intestinal permeability (Table 4). However, serum LPS concentrations, as another measure of intestinal permeability, were not affected by HS. Likewise, HS did not affect the expressions of tight junction-related genes (Table 5). 
Table 4. Effect of heat stress and stocking density on intestinal permeability ${ }^{1}$ in the jejunum of growing broiler chickens.

\begin{tabular}{|c|c|c|c|c|c|}
\hline Item & & PD, mV & Isc, $\mu \mathrm{a} / \mathrm{cm}^{2}$ & $\mathrm{TER}, \Omega / \mathrm{cm}^{2}$ & LPS, EU/mL \\
\hline Temperature $^{2}$ & $\mathrm{SD}^{3}$ & & & & \\
\hline \multirow{2}{*}{ Thermoneutral } & 9 & 187 & 0.7 & 283 & 16.8 \\
\hline & 18 & 179 & 0.6 & 303 & 21.8 \\
\hline \multirow[t]{2}{*}{ Heat stress } & 9 & 112 & 0.8 & 145 & 20.2 \\
\hline & 18 & 129 & 0.7 & 196 & 22.0 \\
\hline $\operatorname{SEM}(n=5)$ & & 29.9 & 0.11 & 29.9 & 5.36 \\
\hline \multicolumn{6}{|l|}{ Main effect } \\
\hline \multicolumn{6}{|l|}{ Temperature } \\
\hline Thermoneutral & & 183 & 0.6 & 293 & 19.3 \\
\hline Heat & & 120 & 0.7 & 170 & 21.1 \\
\hline $\operatorname{SEM}(n=10)$ & & 21.2 & 0.08 & 21.1 & 3.59 \\
\hline \multicolumn{6}{|l|}{ SD } \\
\hline 9 & & 149 & 0.7 & 214 & 18.5 \\
\hline 18 & & 154 & 0.6 & 250 & 21.9 \\
\hline $\operatorname{SEM}(n=10)$ & & 21.2 & 0.08 & 21.1 & 3.59 \\
\hline$p$-Value & $\mathrm{df}$ & & & & \\
\hline Temperature & 1 & 0.052 & 0.482 & $<0.001$ & 0.721 \\
\hline SD & 1 & 0.880 & 0.538 & 0.247 & 0.502 \\
\hline Temperature $\times$ SD & 1 & 0.677 & 0.627 & 0.613 & 0.751 \\
\hline
\end{tabular}

${ }_{1} \mathrm{PD}$, trans-epithelial voltage; Isc, short circuit current; TER, trans-epithelial electrical resistance; LPS, serum lipopolysaccharide (EU, endotoxin units $/ \mathrm{ml}) .{ }^{2}$ Average ambient temperatures were $20{ }^{\circ} \mathrm{C}$ and $27.8^{\circ} \mathrm{C}$ for thermoneutral conditions and heat stress conditions, respectively. ${ }^{3}$ Stocking density $=$ number of birds per square meter (birds $/ \mathrm{m}^{2}$ ).

Table 5. Effect of heat stress and stocking density on tight junction-related gene expression ${ }^{1}$ in the jejunal mucosa of growing broiler chickens.

\begin{tabular}{lccccc}
\hline \multicolumn{1}{c}{ Item } & & ZO-1 & OCLN & CLDN-1 & JAM-2 \\
\hline Temperature ${ }^{2}$ & $\mathrm{SD}^{3}$ & & & & \\
Thermoneutral & 9 & 0.84 & 1.82 & 1.48 & 1.59 \\
& 18 & 0.95 & 1.14 & 1.30 & 0.98 \\
Heat stress & 9 & 1.52 & 1.32 & 1.49 & 1.29 \\
& 18 & 0.57 & 0.47 & 0.44 & 0.46 \\
\hline SEM $(n=5)$ & & 0.452 & 0.384 & 0.489 & 0.415 \\
\hline Main effect & & & & & \\
Temperature & & 0.90 & 1.48 & 1.39 & 1.29 \\
Thermoneutral & & 1.05 & 0.89 & 0.97 & 0.87 \\
Heat & & 0.304 & 0.258 & 0.328 & 0.278 \\
\hline SEM $(n=10)$ & & & & & \\
\hline SD & & 1.18 & 1.57 & 1.48 & 1.44 \\
9 & & 0.76 & 0.81 & 0.87 & 0.72 \\
18 & & 0.304 & 0.258 & 0.328 & 0.278 \\
\hline SEM $(n=10)$ & $\mathrm{df}$ & & & & \\
\hline$p$-Value & 1 & 0.728 & 0.120 & 0.364 & 0.297 \\
Temperature & 1 & 0.327 & 0.048 & 0.196 & 0.079 \\
SD & 1 & 0.221 & 0.817 & 0.350 & 0.775 \\
Temperature $\times$ SD & & & & \\
\hline
\end{tabular}

${ }^{1}$ ZO-1, zonula occludens-1; OCLN, occludin; CLDN-1, claudin-1; JAM-2, junctional adhesion molecules-B. ${ }^{2}$ Average ambient temperatures were $20^{\circ} \mathrm{C}$ and $27.8^{\circ} \mathrm{C}$ for thermoneutral conditions and heat stress conditions, respectively. ${ }^{3}$ Stocking density $=$ number of birds per square meter $\left(\right.$ birds $\left./ \mathrm{m}^{2}\right)$. 
High SD had no effects on TER values and serum LPS concentrations. However, high SD decreased $(p<0.05)$ OCLN expression, but had no effect on ZO-1, CLDN-1, and JAM-2 expression.

\section{Discussion}

There were no significant interactions between HS and SD for the growth performance, breast meat quality, and intestinal barrier function of broiler chickens in the current experiment. These results were surprising because both HS and high SD are well-known stressors of broiler chickens, and were expected to have synergistic negative effects on broiler chickens. Imaeda [20] reported that broiler mortality resulting from high SD was more considerable when birds were raised under a hot season. Likewise, Najafi [12] reported that serum concentrations of stress indicators including corticosterone, ceruloplasmin, and ovotransferrin in broiler chickens were increased by high SD and the extent of increased stress responses was greater under HS conditions than under TN conditions. However, Imaeda [20] and Najafi et al. [12] observed no negative interaction between HS and SD for the growth performance of broiler chickens, which agrees with our findings that high SD decreased BWG and FI, regardless of ambient temperature, and the extent of the decreases in BWG and FI was not significantly different between HS and TN conditions. These results are difficult to explain because of limited information on the interactive effects of HS and SD on poultry. However, it is speculated that stress responses may be synergistic between HS and high SD, but it is likely insufficient to exhibit the obvious reduction in the growth performance of broiler chickens raised under the conditions of the current experiment. It should be noted that the interactive effects of HS and SD may vary with intensities and durations of HS and high SD during broiler production.

Although there were no interactions between HS and SD in this experiment, the main effects of HS and high SD were significant for some measurements of the growth performance, breast meat quality, and intestinal barrier function in broiler chickens. As expected, birds raised under HS conditions had decreased BWG and FI as compared to those raised under TN conditions, which indicated that average ambient temperature of $27.8^{\circ} \mathrm{C}$ in the present experiment induced HS for growing broiler chickens. Likewise, high SD (i.e., 18 birds $\left./ \mathrm{m}^{2}\right)$ decreased BWG and FI than low SD $\left(9\right.$ birds $\left./ \mathrm{m}^{2}\right)$, indicating that high SD in this experiment was stressful for growing broiler chickens. This result agreed with previous experiments, which reported that a SD of more than $16.0 \mathrm{birds} / \mathrm{m}^{2}$ had negative effects on the growth performance of growing broiler chickens [7,21,22]. However, the upper limits of high SD for broiler chickens may vary with breed, environment, rearing systems, experimental periods, and intensity of $\mathrm{SD}[8,12,23]$. In our previous experiment [11], up to 25.3 birds $/ \mathrm{m}^{2}$ of SD during 1 to 28 days of age had no adverse effects on the growth performance of broiler chickens raised in battery cages, whereas 18 birds $/ \mathrm{m}^{2}$ of SD during 21 to 35 days of age in this experiment decreased the growth performance of broiler chickens raised in floor pens.

The quality of most breast meat were unaffected by HS and high SD although there were significant main effects of HS and high SD on some measurements. However, all values for breast meat quality were within the normal range of the general breast meat quality of broiler chickens. Therefore, it is likely that either HS or high SD had little negative effect on breast meat quality. However, previous experiments reported that HS produced undesirable meat quality of broiler chickens $[24,25]$. Thus, the reason for these inconsistent results for HS may be due to the variations in experimental factors including breed, slaughtering age, and the extent and duration of HS among experiments. However, there was little negative effect of high SD on meat quality as observed in this experiment, which is in agreement with previous experiments [11,21].

It is well documented that HS induces various physiological problems including immune dysfunctions, endocrine disturbances, respiratory alkalosis, and increased oxidative stress in poultry [2-4]. Moreover, HS decreases blood flow to intestinal tissues by increasing blood flow to peripheral tissues, which leads to a reduction in nutrient and oxygen supply and, therefore, impairs intestinal health and functions [5]. One of the critical functions in the GIT is to prevent the permeation of harmful substances in the lumen into the body, which is often called the intestinal 
barrier function [5]. Intestinal barrier function is frequently determined by intestinal permeability (i.e., gut leakage) measured with TER values for intestinal tissues and blood LPS concentrations $[5,11]$. Decreased TER values for intestinal tissues and increased LPS concentrations in the blood represent increased intestinal permeability. Furthermore, intestinal barrier function is highly associated with the integrity of mucosal tight junction, which is a sealing protein complex between enterocytes in the GIT $[6,11]$. Decreased expression of tight junction-related genes and proteins in the GIT is often correlated with decreased intestinal barrier function [6,11]. Thus, we measured jejunal TER values, serum LPS concentrations, and the expression of four important tight junction-related genes (ZO-1, $O C L N, C L D N-1$, and $J A M-2)$ in the jejunal mucosa.

The observation of decreased TER values in the jejunum of broiler chickens raised under HS conditions indicated that HS increased intestinal permeability in broiler chickens. This result is in accordance with the findings of previous experiments reporting decreased intestinal TER values in broiler chickens exposed to HS [26,27]. However, high SD (i.e., $18 \mathrm{birds} / \mathrm{m}^{2}$ ) under the condition of the present experiment had no effect on TER values, which differs from our previous findings where increasing SD from 15.2 to 30.4 birds $/ \mathrm{m}^{2}$ exhibited a linear reduction in jejunal TER values [11]. This inconsistent result is likely caused by the variation in rearing systems and intensity of SD among experiments. In our previous experiment, all birds were raised in battery cages under TN conditions and a reduction in TER values became more obvious when birds were raised at more than 25.3 birds $/ \mathrm{m}^{2}$ of SD. Therefore, it is likely that $18 \mathrm{birds} / \mathrm{m}^{2}$ of SD under the current conditions was unlikely to decrease intestinal barrier function. Neither HS nor high SD influenced the serum LPS concentrations in the current experiment. It has been reported that serum LPS concentrations are negatively correlated with TER values because increased intestinal permeability accelerates the passage of luminal LPS into the body [5]. We also reported previously that serum LPS concentrations were negatively associated with TER values in broiler chickens raised in battery cages with different SD [11]. However, this relationship was not identified in the current experiment. The reason for this discrepancy is unclear; however, it may be related to less intensity of the current conditions of HS and high SD as compared to those in previous experiments [11,12,26]. In addition, variations in microbial populations among experiments may be another possible reason for inconsistent results because serum LPS originates from luminal LPS, which is a cell wall component of intestinal bacteria [5], and differences in rearing systems (battery cages vs. floor pens) and environmental temperatures can influence microbial populations [26,28].

$O C L N, C L D N-1$, and JAM-2 are the main component proteins of tight junctions and ZO-1 acts as a plague protein connecting between those tight junction proteins and cytoskeletons [29]. The proper expression of tight junction-related genes and proteins plays an important role in maintaining intestinal barrier function and controlling paracellular permeability [29]. Decreased expressions of tight junction-related genes and proteins in the intestinal mucosa of broiler chickens have been reported for OCLN and ZO-1 proteins by HS [26] and for ZO-1 and JAM-2 genes by high SD [11]. However, we observed no main effects of HS and high SD on tight junction-related gene expression in the jejunal mucosa, which indicate that our experimental conditions of HS and SD cannot largely affect the integrity of mucosal tight junction. However, we found decreased TER values under HS conditions although TER values were not affected by high SD. This inconsistent finding may indicate that the expressions of tight junction-related genes and proteins are not always correlated with intestinal permeability measured by TER values. However, there is a possibility that the correlation may become obvious only when changes in the expressions of tight junction-related genes and proteins exceed a certain level. Moreover, it should also be noted that we may fail to detect significance due to the large inherent variations in tight junction-related gene expressions among individual birds because HS decreased expressions of OCLN, CLDN-1, and JAM-2 by more than $30 \%$, whereas high SD decreased expressions of all four genes by more than $36 \%$. Further research is required to elucidate the relationship between intestinal permeability and the expression of tight junction-related genes and proteins. 


\section{Conclusions}

No interactive effects of HS and SD are observed on the growth performance, breast meat quality, and intestinal barrier function of growing broiler chickens. In the conditions of the current experiment, both HS and high SD decrease broiler performance with little negative effect on breast meat quality. Intestinal barrier function is decreased by HS in growing broiler chickens, but the decrease in intestinal barrier function by high SD is not considerable in the present experiment.

Author Contributions: Conceptualization, D.G. and D.Y.K.; Methodology, D.G., J.H.K., and G.H.P; Software, D.G.; Validation, D.G., J.H.K., J.B.D.R., and D.Y.K.; Formal Analysis, D.G.; Investigation, D.G., J.H.K., G.H.P., J.B.D.R., and D.Y.K. Resources, D.Y.K.; Data Curation, D.G.; Writing-Original Draft Preparation, D.G., J.H.K.; Writing-Review \& Editing, J.H.K. and D.Y.K.; Visualization, D.G., G.H.P., and J.B.D.R.; Supervision, D.Y.K.; Project Administration, D.Y.K.; Funding Acquisition, D.Y.K.

Funding: This research was supported by Basic Science Research Program through the National Research Foundation of Korea (NRF) funded by the Ministry of Science, ICT and Future Planning (NRF-2016R1C1B1009323).

Conflicts of Interest: The authors declare no conflicts of interest.

\section{References}

1. Zhang, C.; Zhao, X.H.; Yang, L.; Chen, X.Y.; Jiang, R.S.; Jin, S.H.; Geng, Z.Y. Resveratrol alleviates heat stress-induced impairment of intestinal morphology, microflora, and barrier integrity in broilers. Poult. Sci. 2017, 96, 4325-4332. [CrossRef] [PubMed]

2. Teeter, R.G.; Smith, M.O.; Owens, F.N.; Arp, S.C.; Sangiah, S.; Breazile, J.E. Chronic heat stress and respiratory alkalosis: Occurrence and treatment in broiler chicks. Poult. Sci. 1985, 64, 1060-1064. [CrossRef] [PubMed]

3. Sohail, M.U.; Ijaz, A.; Yousaf, M.S.; Ashraf, K.; Zaneb, H.; Aleem, M.; Rehman, H. Alleviation of cyclic heat stress in broilers by dietary supplementation of mannan-oligosaccharide and Lactobacillus-based probiotic: Dynamics of cortisol, thyroid hormones, cholesterol, C-reactive protein, and humoral immunity. Poult. Sci. 2010, 89, 1934-1938. [CrossRef] [PubMed]

4. Lara, L.J.; Rostagno, M.H. Impact of Heat Stress on Poultry Production. Animals 2013, 3, 356-369. [CrossRef] [PubMed]

5. Lambert, G.P. Stress-induced gastrointestinal barrier dysfunction and its inflammatory effects. J. Anim. Sci. 2009, 87, E101-E108. [CrossRef]

6. Shin, J.E.; Kim, J.H.; Goo, D.; Han, G.P.; Pitargue, F.M.; Kang, H.K.; Kil, D.Y. Effect of dietary supplementation of betaine on productive performance, egg quality and jejunal tight junction-related gene expression in laying hens raised under hot environmental conditions. Livest. Sci. 2018, 214, 79-82. [CrossRef]

7. Puron, D.; Santamaria, R.; Segura, J.C.; Alamilla, J.L. Broiler performance at different stocking densities. J. Appl. Poult. Res. 1995, 4, 55-60. [CrossRef]

8. Estevez, I. Density allowances for broilers: Where to set the limits? Poult. Sci. 2007, 86, 1265-1272. [CrossRef] [PubMed]

9. Bessei, W. Welfare of broilers: A review. World's Poult. Sci. J. 2006, 62, 455-466. [CrossRef]

10. Cengiz, O.; Koksal, B.H.; Tatli, O.; Sevim, O.; Ahsan, U.; Uner, A.G.; Ulutas, P.A.; Beyaz, D.; Buyukyoruk, S.; Yakan, A.; et al. Effect of dietary probiotic and high stocking density on the performance, carcass yield, gut microflora, and stress indicators of broilers. Poult. Sci. 2015, 94, 2395-2403. [CrossRef]

11. Goo, D.; Park, G.H.; Han, G.P.; Choi, H.S.; Kim, J.H.; Kil, D.Y. Effect of stocking density and sex on growth performance, meat quality, and intestinal barrier function in broiler chickens. Poult. Sci. 2019, 98, 1153-1160. [CrossRef]

12. Najafi, P.; Zulkifli, I.; Jajuli, N.A.; Farjam, A.S.; Ramiah, S.K.; Amir, A.A.; O'Reily, E.; Eckersall, D. Environmental temperature and stocking density effects on acute phase proteins, heat shock protein 70 , circulating corticosterone and performance in broiler chickens. Int. J. Biometeorol. 2015, 59, 1577-1583. [CrossRef] [PubMed]

13. Cobb Broiler Management Guide. Available online: https:/ / cobbstorage.blob.core.windows.net/guides / 9109a8e0-1815-11e9-9c88-c51e407c53ab (accessed on 10 February 2019). 
14. Kim, J.H.; Jung, H.; Pitargue, F.M.; Han, G.P.; Choi, H.S.; Kil, D.Y. Effect of dietary calcium concentrations in low non-phytate phosphorus diets containing phytase on growth performance, bone mineralization, litter quality, and footpad dermatitis incidence in growing broiler chickens. Asian-Australas. J. Anim. Sci. 2017, 30, 979-983. [CrossRef]

15. Kim, C.H.; Kim, G.B.; Chang, M.B.; Bae, G.S.; Paik, I.K.; Kil, D.Y. Effect of dietary supplementation of Lactobacillus-fermented Artemisia princeps on growth performance, meat lipid peroxidation, and intestinal microflora in Hy-line Brown male chickens. Poult. Sci. 2012, 91, 2845-2851. [CrossRef] [PubMed]

16. Aznar, R.; Alarcon, B. On the specificity of PCR detection of Listeria monocytogenes in food: A comparison of published primers. Syst. Appl. Microbiol. 2002, 25, 109-119. [CrossRef]

17. Thomsen, R.; Sølvsten, C.A.E.; Linnet, T.E.; Blechingberg, J.; Nielsen, A.L. Analysis of qPCR data by converting exponentially related $\mathrm{Ct}$ values into linearly related $\mathrm{x} 0$ values. J. Bioinform. Comput. Biol. 2010, 8, 885-900. [CrossRef] [PubMed]

18. Ruhnke, I.; Rohe, I.; Meyer, W.; Kroger, S.; Neumann, K.; Zentek, J. Method for the preparation of mucosal flaps from the jejunum of laying hens for transporter studies in Ussing chambers. Arch. Anim. Nutr. 2013, 67, 161-168. [CrossRef]

19. Gabler, N.K.; Spencer, J.D.; Webel, D.M.; Spurlock, M.E. In utero and postnatal exposure to long chain (n-3) PUFA enhances intestinal glucose absorption and energy stores in weanling pigs. J. Nutr. 2007, 137, 2351-2358. [CrossRef]

20. Imaeda, N. Influence of the stocking density and rearing season on incidence of sudden death syndrome in broiler chickens. Poult. Sci. 2000, 79, 201-204. [CrossRef]

21. Zuowei, S.; Yan, L.; Yuan, L.; Jiao, H.; Song, Z.; Guo, Y.; Lin, H. Stocking density affects the growth performance of broilers in a sex-dependent fashion. Poult. Sci. 2011, 90, 1406-1415. [CrossRef]

22. Houshmand, M.; Azhar, K.; Zulkifli, I.; Bejo, M.H.; Kamyab, A. Effects of prebiotic, protein level, and stocking density on performance, immunity, and stress indicators of broilers. Poult. Sci. 2012, 91, $393-401$. [CrossRef] [PubMed]

23. Buijs, S.; Keeling, L.; Rettenbacher, S.; Van Poucke, E.; Tuyttens, F.A.M. Stocking density effects on broiler welfare: Identifying sensitive ranges for different indicators. Poult. Sci. 2009, 88, 1536-1543. [CrossRef]

24. Sandercock, D.A.; Hunter, R.R.; Nute, G.R.; Mitchell, M.A.; Hocking, P.M. Acute heat stress-induced alterations in blood acid-base status and skeletal muscle membrane integrity in broiler chickens at two ages: Implications for meat quality. Poult. Sci. 2001, 80, 418-425. [CrossRef]

25. Zhang, Z.Y.; Jia, G.Q.; Zuo, J.J.; Zhang, Y.; Lei, J.; Ren, L.; Feng, D.Y. Effects of constant and cyclic heat stress on muscle metabolism and meat quality of broiler breast fillet and thigh meat. Poult. Sci. 2012, 91, 2931-2937. [CrossRef]

26. Song, J.; Xiao, K.; Ke, Y.L.; Jiao, L.F.; Hu, C.H.; Diao, Q.Y.; Shi, B.; Zou, X.T. Effect of a probiotic mixture on intestinal microflora, morphology, and barrier integrity of broilers subjected to heat stress. Poult. Sci. 2014, 93, 581-588. [CrossRef] [PubMed]

27. Song, J.; Jiao, L.F.; Xiao, K.; Luan, Z.S.; Hu, C.H.; Shi, B.; Zhan, X.A. Cello-oligosaccharide ameliorates heat stress-induced impairment of intestinal microflora, morphology and barrier integrity in broilers. Anim. Feed Sci. Technol. 2013, 185, 175-181. [CrossRef]

28. Kim, J.H.; Kim, J.W.; Lee, B.B.; Lee, G.I.; Lee, J.H.; Kim, G.B.; Kil, D.Y. Effect of dietary supplementation of bacteriophage on growth performance and cecal bacterial populations in broiler chickens raised in different housing systems. Livest. Sci. 2014, 170, 137-141. [CrossRef]

29. Ulluwishewa, D.; Anderson, R.C.; McNabb, W.C.; Moughan, P.J.; Wells, J.M.; Roy, N.C. Regulation of tight junction permeability by intestinal bacteria and dietary components. J. Nutr. 2011, 141, 769-776. [CrossRef]

(C) 2019 by the authors. Licensee MDPI, Basel, Switzerland. This article is an open access article distributed under the terms and conditions of the Creative Commons Attribution (CC BY) license (http:// creativecommons.org/licenses/by/4.0/). 